Research Article

\title{
The Coupling Coordination Evaluation of Sustainable Development between Urbanization, Housing Prices, and Affordable Housing in China
}

\author{
Lida Wang $\mathbb{D}^{1},{ }^{1}$ Xian Rong $\mathbb{D}^{1,2}$ and Lingling $M u \mathbb{D}^{3}$ \\ ${ }^{1}$ School of Civil and Transportation Engineering, Hebei University of Technology, Tianjin 300401, China \\ ${ }^{2}$ Hebei Civil Engineering Technology Research Center, Tianjin 300401, China \\ ${ }^{3}$ School of Economics and Management, Hebei University of Technology, Tianjin 300401, China
}

Correspondence should be addressed to Lingling Mu; lingmu1020@163.com

Received 28 May 2021; Revised 31 July 2021; Accepted 17 August 2021; Published 25 August 2021

Academic Editor: Lei Xie

Copyright (c) 2021 Lida Wang et al. This is an open access article distributed under the Creative Commons Attribution License, which permits unrestricted use, distribution, and reproduction in any medium, provided the original work is properly cited.

For the past few years, China's urbanization process has been in a state of rapid and variable development. With many migrants flowing from rural to urban area, the change in the urban structure and the trend of the economic development has led to a rapid development of the real estate market. However, the conflict between the migrants and the local low-and middle-income groups in respect of demand for basic housing has become a concern. Based on Chinese time-series data from 2008 to 2018 , this study establishes an evaluation indicator system to consider the influence of urbanization, housing prices, and affordable housing and analyzes the comprehensive development level and coordination relationship using the methods of range standardization, entropy weight model, and coupling coordination. The results show that the comprehensive development levels of housing prices and affordable housing are both in a state of fluctuating growth. From 2008 to 2018, the coupling degree between urbanization, housing prices, and affordable housing was high, while the coupling coordination degree between the three subsystems increased from reluctant coordination to satisfactory coordination; this clearly shows that the relationships between urbanization, housing prices, and affordable housing are mutually coupled and promoted. Furthermore, based on the coupling coordination relationships between the three subsystems, this study discusses the sustainable development of urbanization and provides some suggestions for regional government. The conclusions have practical significance for China and other developing countries to coordinate housing prices and affordable housing in the process of rapid urbanization.

\section{Introduction}

With China's rapidly increasing level of urbanization, social problems of living standards have gradually arisen. Cities are centres of people's economic activities and are essential for industrialization and urbanization [1]. Therefore, the sustainable development of the nation depends on the sustainable development of the cities [2]. Cities, in close collaboration with adjacent areas and towns, constitute an organized system for the exchange of materials and manpower [3]. Urbanization is a physical process that can lead to urban agglomeration and an unsustainable imbalance between the supply of and demand for resources in urban areas [4].
According to the national statistics, China's urban population rose from 459.06 million in 2000 to 831.37 million in 2018 [5]. The urban population constituted approximately $59.58 \%$ of the national total in 2018 , representing an average growth rate of approximately $12.59 \%$ over the previous decade [5]. In 2017, China's total migrant population was about 244 million, which accounted for $17.55 \%$ of the national population; the provincial migrant population accounted for $63.5 \%$ of the national migrant population [6]. From Figure 1, in the last decade, the urbanization rate rose from $46.99 \%$ in 2008 to $59.58 \%$ in 2018 .

Data sources: housing average prices and urbanization rates come from the State Statistics Bureau; migrant 


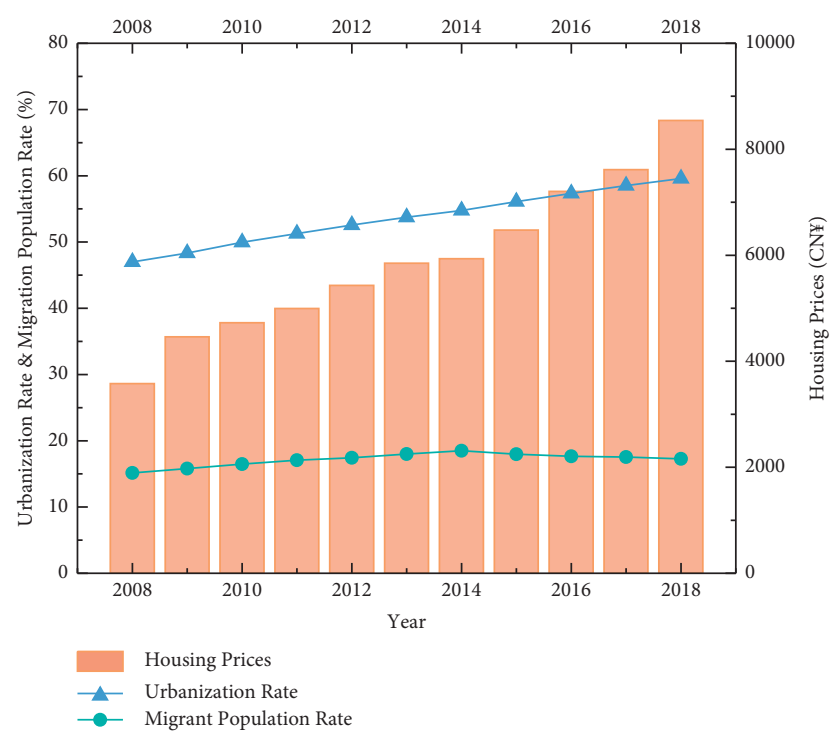

FIGURE 1: China's housing average prices, migrant population rates, and urbanization rates: 2008-2018.

population rates come from the National Health and Family Planning Commission Migrant Population Service Centre.

When population flows from the rural into the urban areas, the development of the urbanization process brings about an interaction between urbanization and the real estate market, the demand for housing increases, and the development of the real estate markets in the urban agglomeration areas is facilitated [7]. According to data from the National Bureau of Statistics in China, the average price of housing rose from CN¥ 3800 in 2008 to CN¥ 8737 in 2018 , representing an increase of over $138 \%$ over the decade (Figure 1) [8]. The rapid increase in housing prices is a significant housing concern [9]. Given the currently densely populated urban agglomeration areas, the economic problem of housing demand for the middle-low-income community becomes a multifactor social problem. Chairman Xi reminded us that housing was for living in and not for investment, in the CCP's 19th National Congress Report [10]. Premier of State Council, Li Keqiang, proposed the establishment of a multisubject supply, multichannel security rent-and-purchase housing system to guarantee housing security for residents [11]. Furthermore, to balance demand and supply in the real estate market and to guarantee housing for residents with housing difficulties, the Chinese government has frequently introduced management policies to improve the affordability of housing mechanisms [12]. Therefore, given the high housing prices and rapid urbanization, it is necessary to search for affordable housing mechanisms to ensure the health and sustainability of the real estate market as well as residents' livelihood.

Given the rapidly increasing housing prices and the need for a sustainable development of the real estate market, domestic and overseas scholars have focused on factors that drive housing prices. In the literature, housing price factors can be divided into macro- and microaspects. Among the macroaspects, previous studies have focused on society [13], politics [14], macroeconomic factors [15, 16], supply and demand relationships [17], environment [18], and physical geography [19]. Among the microaspects, studies have focused on some real estate characteristics, such as the living environment [20], infrastructural facilities [21], and surrounding resources [22], as well as on household and household buyers' individual characteristics [23].

Liu and Chau established three test methodologies (unit root test, co-integration test, and granger causality test) to calculate related data and demonstrated that the urbanization rate could positively predict real estate market investment; the study found that urbanization could increase "living demand," "productive demand," "consumption demand," and "investment demand" [7]. Additionally, the authors established different models to calculate specific values of urbanization rates and real estate market demands. Zhang and Zheng use the STATA statistical software for a quantitative analysis of the variables of price, income, and urbanization rate, based on 2003-2007 panel data, and find that urbanization can positively affect real estate demand. The results show that when the urbanization rate increases by $1 \%$, the housing demand will increase by $5.861 \%$ [24]. Wang also analyzed the impact of urbanization on real estate market demand; the study found that when the urbanization rate increased by $1 \%$, the merchandisable area of the real estate market would increase by $5.21 \%$ [25]. These studies proved the urbanization can effectively promote urban housing demand. Furthermore, how to solve the increasing housing demand has become one important research point of the sustainable development of real estate market. In addition to the research on the relationship between urbanization development and real estate demand, many scholars have studied the relationship between urbanization development and housing prices.

Gong et al. use econometric analysis methods to analyze panel data on 273 cities in China, for the period 2006-2015; the authors find that the decomposition factors of urbanization affect the urban housing demand and significantly impact the housing price level in China [26]. Wang and Xu measure the impact of population migration on housing prices, based on the Beijing panel data model; they find that when the population increases by $1 \%$, the average price of commercial housing will increase by CN¥ $9158.023 / \mathrm{m}^{2}$ [27]. Wang et al. study the impact of inter-regional people turnover and rural-urban migration on the housing price level, based on cross-sectional data [13]. The authors find that when the inter-regional people turnover increases by $1 \%$, housing prices increase by $0.701 \%$; when the rural-urban migration increases by $1 \%$, housing prices increase by $0.343 \%$. Wang and Chen construct a vector autoregressive model (VAR) to study the impact of population migration on housing prices in different provinces and find that the influence of population migration on housing prices is greater in the eastern region of China than in the western region [28]. Ren and Chen construct a panel VAR model (PVAR) to analyze data on 30 Chinese provinces from 2001 to 2016; the dynamic results show an inter-relationship between urbanization, urban-rural income gap, and housing prices and an obvious volatility of the impact of housing prices on 
urbanization [29]. Scholars have researched the correlation between urbanization and housing prices through different methods and found that the promotion of urbanization will increase housing prices. However, with the increase of housing prices, the housing demands of low- and middleincome families and migrant workers cannot be properly addressed, which should be considered in the system research of real estate market in the process of urbanization.

Most of the previous studies on urbanization and affordable housing are related to social relations and human rights, with housing rights usually regarded as a basic human right with a broader scope than ownership [30, 31]. According to King, housing rights can be regarded as freedom rights which, as a fundamental right, can depend on other basic human functions [32]. The 2016 Habitat III Conference proposed to support the gradual realization of the right to housing and to support governments to implement urban planning strategies, establish affordable housing systems, and gradually realize adequate housing [33]. Concerning the problem of rising housing demand due to urbanization, most scholars focus on government policies and regulations on affordable housing.

Research on affordable housing and the real estate market is different in developing and developed countries. First, developed countries have passed the housing increment stage and are in the housing stock stage; therefore, research on the crowding-out effect between affordable housing and commercial housing is relatively new. Murray studies the relationship between affordable housing construction and housing inventories in the US; the study entails the impact of the public housing subsidy program on inventory, from the viewpoint of the crowding-out effect [34]. The results show that the housing security policy has a crowding-out effect on private housing investment; therefore, housing supply is not affected by the housing subsidy program. Lee constructs a VAR model to analyze the crowding-out effect between affordable housing and the real estate market with panel data on Korean real estate; the results show that there is a Granger causality mutual crowding-out effect between investment in affordable housing by government and investment in private real estate [35]. From a housing demand perspective, scholars have focused on affordable housing policies and the rent level in the real estate market. Susin and Laferrère study the impact of a housing subsidy policy on the housing rent price level in the US and France, respectively, and find that a rent subsidy increases the rent price level $[36,37]$. Crews Cutts and Olsen undertake an empirical study on the relationship between housing demand and housing subsidy policies, which shows that when housing subsidy standards are reduced at all levels to adjust the demand structure in the market, the same investment can expand the coverage of housing affordability [38]. Similarly, Sinai and Waldfogel analyzed whether housing subsidy policies increased regional housing demand and showed that the crowding-out effect of increasing affordable housing demand was small [39]. In addition, the affordable housing system in developed countries was established early and relatively mature. The research on crowding out effect, transformation mechanism, and balance status between affordable housing and commercial housing become the important point in recent years.

For developing countries, the real estate market is in the housing increment state, in which the construction of affordable housing has a crowding-out effect on the supply of commercial housing, housing demand, and housing price levels. Furthermore, Chinese scholars have obtained mixed results on the impact of affordable housing construction on commercial housing prices. Zhang's study on the relationship between land supply, affordable housing construction, and housing price level, using the ordinary least squares (OLS) and two-stage least squares (2SLS) methods, showed that the land supply scale of affordable housing had a significant restraining effect on the housing price level [40]. In a study by Luo et al., the authors constructed a VAR model to analyze the relationship between affordable housing and commercial housing; the results were consistent with those of Zhang [41]. Liu and Li construct a dynamic-panel threshold model to investigate the relationship between affordable housing and the housing price level. The results show that affordable housing can decrease the housing price level only when it has small supply scales; however, overpromoting the construction of affordable housing on a large scale will have the opposite effect on the housing price level [42]. Wang and Jiang analyze the "substitution effect" and "crowding-out effect" of affordable housing on commercial housing demand to illustrate the mechanism through which affordable housing construction impacts the commercial housing price level. The results show that, in the central cities, affordable housing addresses the residential affordability needs of low- and middle-income families, while, in areas with severe real estate bubbles, affordable housing plays a regulatory and controlling role, which is conducive to improving people's livelihoods and to a sound development of the real estate market [43]. However, the research studies for developing countries focus on demonstrating the regulating effect of affordable housing on the prices of commercial housing and the establishment of affordable housing system and its mechanism.

Different development stage of real estate market cause different research studies. For developed countries, the previous research studies on the relationship between affordable housing and housing prices are relatively mature, while the research studies for developing countries are still exploring the influencing mechanisms and related policies based on national background. Considering the systematic interaction between affordable housing and housing prices in the process of urbanization, this study believes that the relationships among the urbanization, housing price, and affordable housing subsystems are not completely independent, but are mutually relevant (Figure 2).

The relationships among the three subsystems form a system with dynamic, complex characteristics [44]. Given new urban population inflow, the demand for housing, which includes commercial and affordable housing, rises. When housing demand increases, housing prices increase, promoting regional economic development. However, high housing price levels could restrain the inflow of people from rural to urban areas, which is equivalent to holding back the 


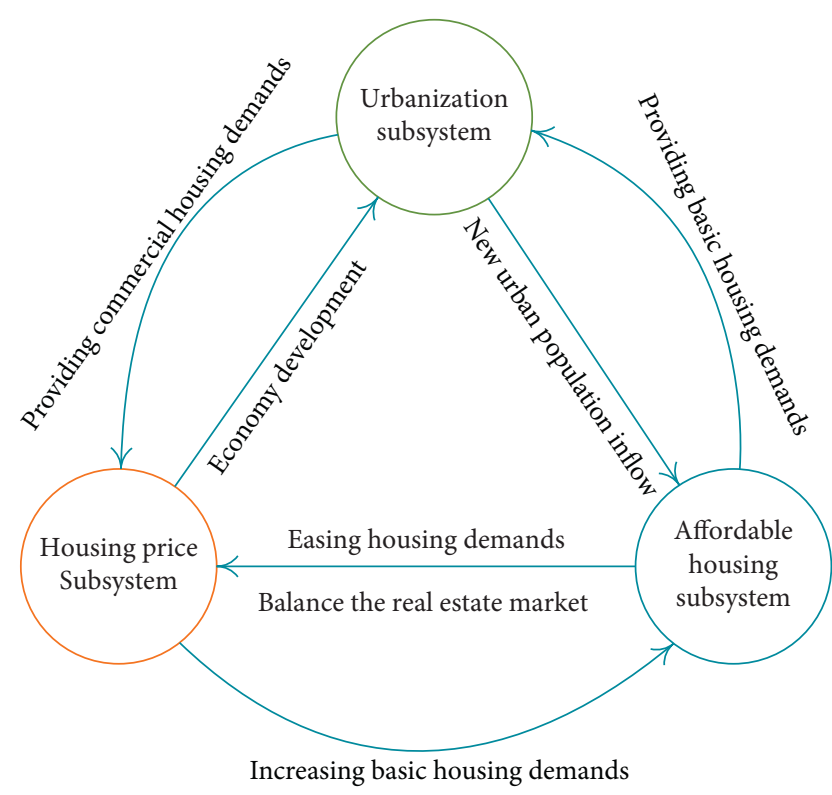

FIGURE 2: Coupling relationship among urbanization, housing prices, and affordable housing.

progress of urbanization. In the process of urbanization, most people moving into urban areas, such as graduate students and migrant workers, have basic housing needs as they do not have enough fixed assets [45]. The development of an affordable housing system can meet migrants' basic housing demands. However, an incomplete affordable housing system can reduce this ability to alleviate basic housing demands, which indirectly restrains the inflow of population from rural to urban areas, thus impeding the process of urbanization. The construction of an urban affordable housing system can solve the problem of the basic demand for housing for local people with housing difficulties, balance the housing demand in a region, control the housing prices, and balance the real estate market. In addition, a rapid increase in housing prices renders commercial housing unaffordable to more people and increases the demand for basic affordable housing in a region.

The coupling relationship between urbanization, housing prices, and affordable housing reflects a sustainable development of cities. Currently, the research problem of the coordination between urbanization, housing prices, and affordable housing requires urgent resolution. Moreover, population migration is at the core of urbanization, while addressing the demand for urban housing is one of the core problems in the sustainable development of cities. Their coupling coordination relationship is an important driving force to stabilize the urban population structure, improve the quality of urbanization, and promote urban economic and social sustainable development. In this study, the research of coupling coordination between urbanization, housing prices, and affordable housing can provide new research ideas for current research fields and provide theoretical basis for relevant departments to make policies for the sustainable development of the real estate market in the process of urbanization.
The coupling coordination degree (CCD) model can measure the interaction relationship between two or more subsystems in a complicated system. Coupling is a physical concept that can be used to indicate the intrinsic relationship between elements in a system [46]. The concept of coordination indicates the degree of harmony between elements of a system and can reflect a system's trend from inharmony to harmony, according to synergy and systems' theories [47]. The CCD model quantifies the interaction within a system and accurately illustrates the internal synergy of each subsystem. Presently, the model is widely used in tourism $[48,49]$, land urbanization $[50,51]$, urban ecology $[52,53]$, environmental development $[54,55]$, and other areas $[56,57]$. However, few studies consider the coordination relationship between urbanization, affordable housing, and real estate market.

This study uses country-level data to explore the coupling coordination relationship between urbanization, affordable housing, and real estate market. Due to data availability, the study only considers the period 2008-2018, with the following objectives:

(1) To establish an indicator system for a comprehensive development level for each subsystem

(2) To construct a CCD model to measure comprehensive indicator characteristic values

(3) To analyze the coupling coordination trend from 2008 to 2018 and the unbalanced status of the three subsystems

\section{Methodology and Data Sources}

2.1. Indicator System Establishment. The indicator system was established based on previous research. The indicators that relate to housing prices, affordable housing, and urbanization vary and are complicated. In Table 1 , the three subsystems are divided into 12 indicators, including 11 positive indicators and 1 negative indicator.

This study establishes a comprehensive indicator system to evaluate the overall system, which combines the three subsystems (urbanization, housing prices, and affordable housing). Although the three subsystems have different structures, functions, origins, and development laws, coordinated development between these subsystems is the final goal of the system because of the interdependency.

2.2. Development of the Entropy Weight Model. The entropy weight method is usually adopted to research the social economy $[1,64]$. In this research, 12 indicators of urbanization, housing prices, and affordable housing subsystems have been accounted by the entropy weight method.

According to Li et al. and Gan et al. $[65,66]$, the steps in the entropy weight method are as follows:

Step 1: normalization of indicator values.

To ensure the accuracy of the evaluation results in a scientific study, the original data indicators should be normalized to eliminate the influence of different indicators on the same unit of measurement [47]. The 
TABle 1: Indicator definition.

\begin{tabular}{|c|c|c|c|c|c|}
\hline Subsystem & Indicator (unit) & & Description & $\begin{array}{l}\text { Positive }(+) \text { or } \\
\text { negative }(-)\end{array}$ & References \\
\hline \multirow{4}{*}{$\begin{array}{l}\text { Urbanization } \\
\text { subsystem }\end{array}$} & Population migration (\%) & N1 & $\begin{array}{l}\text { Expressed as the ratio of the migrant population to } \\
\text { the permanent population }\end{array}$ & $(+)$ & {$[8,58]$} \\
\hline & $\begin{array}{c}\text { Economic development } \\
\text { level (\%) }\end{array}$ & $\mathrm{N} 2$ & Expressed by the ratio of the added value to GDP & $(+)$ & {$[12]$} \\
\hline & Unemployment rate $(\%)$ & N3 & $\begin{array}{c}\text { Expressed by the ratio of the registered urban } \\
\text { unemployment rate }\end{array}$ & $(-)$ & {$[59]$} \\
\hline & Urbanization rate (\%) & N4 & $\begin{array}{l}\text { Expressed by the ratio of the urban residents to the } \\
\text { total number of residents }\end{array}$ & $(+)$ & {$[58,60]$} \\
\hline \multirow{4}{*}{$\begin{array}{l}\text { Housing prices } \\
\text { subsystem }\end{array}$} & $\begin{array}{l}\text { Urban housing prices } \\
\left.\text { (yuan } / \mathrm{m}^{2}\right)\end{array}$ & N5 & $\begin{array}{c}\text { Expressed by the average sales price of commercial } \\
\text { housing }\end{array}$ & $(+)$ & {$[8,12]$} \\
\hline & Real estate investment (\%) & N6 & $\begin{array}{l}\text { Expressed by the ratio of residential housing } \\
\text { investment to fixed asset investment }\end{array}$ & $(+)$ & {$[8]$} \\
\hline & $\begin{array}{l}\text { Income level of high- } \\
\text { medium-income group } \\
\text { (yuan) }\end{array}$ & N7 & $\begin{array}{l}\text { Expressed by the per capita disposable income of } \\
\text { high-medium-income urban residents }\end{array}$ & $(+)$ & {$[58]$} \\
\hline & $\begin{array}{l}\text { Housing price-to-income } \\
\text { ratio }\end{array}$ & N8 & $\begin{array}{l}\text { Expressed by the ratio of the average price of a house } \\
\text { to the average annual income of a family }\end{array}$ & $(+)$ & {$[61,62]$} \\
\hline \multirow{4}{*}{$\begin{array}{l}\text { Affordable } \\
\text { housing subsystem }\end{array}$} & $\begin{array}{l}\text { Urban affordable housing } \\
\text { prices (yuan } / \mathrm{m}^{2} \text { ) }\end{array}$ & N9 & $\begin{array}{c}\text { Expressed by the average sales prices of affordable } \\
\text { housing }\end{array}$ & $(+)$ & {$[58,60]$} \\
\hline & $\begin{array}{l}\text { Affordable housing } \\
\text { expenditure level }(\%)\end{array}$ & N10 & $\begin{array}{l}\text { Expressed by the ratio of affordable security } \\
\text { expenditure to local general budget expenditure }\end{array}$ & $(+)$ & {$[58]$} \\
\hline & $\begin{array}{l}\text { Income level of low-income } \\
\text { group (yuan) }\end{array}$ & N11 & $\begin{array}{l}\text { Expressed by the per capita disposable income of } \\
\text { low-income urban residents }\end{array}$ & $(+)$ & {$[8]$} \\
\hline & $\begin{array}{l}\text { Real estate rent and leasing } \\
\text { price index }\end{array}$ & N12 & $\begin{array}{l}\text { Expressed by the relative number for the trend and } \\
\text { magnitude of the changes in the level of the house } \\
\text { lease price in a certain period }\end{array}$ & $(+)$ & {$[63]$} \\
\hline
\end{tabular}

systems' indicators can be divided into positive and negative indicators; therefore, they should be standardized using formulas (1) and (2), before applying the entropy weight model:

$$
\begin{aligned}
& x_{t i}^{\prime}=\frac{x_{t i}-\min \left(x_{i}\right)}{\max \left(x_{i}\right)-\min \left(x_{i}\right)}, \quad \text { (positive indicator), } \\
& x_{t i}^{\prime}=\frac{\max \left(x_{i}\right)-x_{t i}}{\max \left(x_{i}\right)-\min \left(x_{i}\right)}, \quad \text { (Negative indicator), }
\end{aligned}
$$

where $x_{t i}^{\prime}$ represents the value of the standardized indicator and $x_{t i}$ represents the value of the original indicator. $\max \left(x_{i}\right)$ and $\min \left(x_{i}\right)$ represent the maximum and minimum values of the indicator, respectively.

Step 2: calculating indicator weights.

Initially, the ratio for the indicator $Y_{t i}$ can be calculated by formula (3) to illustrate the contribution of the $i$ th evaluation indicator in the $t$ th year:

$$
Y_{t i}=\frac{X_{t i}^{\prime}}{\sum_{t=1}^{m} X_{t i}^{\prime}}
$$

Thereafter, the entropy for the indicator should be calculated using formula (4), based on the definition of information entropy [49]:

$$
e_{i}=-\frac{1}{\ln m} \sum_{t=1}^{m} Y_{t i} \times \ln Y_{t i}, \quad 0 \leq e_{i} \leq 1
$$

The deviation degree for indicator $i$ can then be calculated based on $e_{i}$, by using

$$
d_{i}=1-e_{i}
$$

From formula (6), the weight of indicator $i$ can be computed. The weight of an indicator is greater when the deviation degree for the indicator becomes larger:

$$
W_{i}=\frac{d_{i}}{\sum_{i=1}^{n} d_{i}}
$$

where $m$ represents the number of years and $n$ represents the number of indicators.

2.3. Coupled Coordination Degree Model. According to Jiang et al. [58], formula (7) can be used to calculate the multisystem CCD:

$$
C_{n}=\left[\frac{\left(\mu_{1} \cdot \mu_{2} \cdots \cdot \mu_{n}\right)}{\left(\mu_{1}+\mu_{2}+\cdots+\mu_{n} / n\right)^{n}}\right]^{1 / n} .
$$

Formula (7) can be mathematically manipulated into formula (8): 
TABLE 2: Classification of coordinated development of urbanization, housing prices, and affordable housing.

\begin{tabular}{lcc}
\hline Coupling coordination stage & Indicator value & Coupling coordination classification \\
\hline & $0.0000 \leq D<0.1000$ & Extreme maladjustment \\
I Low-level stage & $0.1000 \leq D<0.2000$ & Serious maladjustment \\
& $0.2000 \leq D<0.3000$ & Moderate maladjustment \\
II Antagonism stage & $0.3000 \leq D<0.4000$ & Low maladjustment \\
& $0.4000 \leq D<0.5000$ & Marginal maladjustment \\
III Running-in stage & $0.5000 \leq D<0.6000$ & Reluctant coordination \\
& $0.6000 \leq D<0.7000$ & Initial coordination \\
IV high-level stage & $0.7000 \leq D<0.8000$ & Moderate coordination \\
& $0.8000 \leq D<0.9000$ & Satisfactory coordination \\
\end{tabular}

$$
C_{n}=n\left\{\frac{\left(\mu_{1} \cdot \mu_{2} \cdots \mu_{n}\right)}{\left(\mu_{1}+\mu_{2}+\cdots+\mu_{n}\right)^{n}}\right\}^{1 / n}
$$

In this study, three systems are calculated using formula (8); thus, when $n=3$, the formula yields the following:

$$
\begin{gathered}
C_{3}=3\left\{\frac{\left(\mu_{1} \cdot \mu_{2} \cdot \mu_{3}\right)}{\left(\mu_{1}+\mu_{2}+\mu_{3}\right)^{3}}\right\}^{1 / 3}, \\
\left\{\begin{array}{l}
\mu_{1}=\sum_{i=1}^{n} a_{i} \cdot x_{i}, \\
\mu_{2}=\sum_{i=1}^{n} b_{i} \cdot x_{i}, \\
\mu_{3}=\sum_{i=1}^{n} c_{i} \cdot x_{i},
\end{array}\right. \\
T=\alpha \cdot \mu_{1}+\beta \cdot \mu_{2}+\gamma \cdot \mu_{3}, \\
D=(C \cdot T)^{\theta},
\end{gathered}
$$

where $C$ is the coupling degree, $D$ is the CCD, $\mu_{1}, \mu_{2}$, and $\mu_{3}$ represent the subsystem comprehensive development levels for urbanization, housing prices, and affordable housing, respectively, $T$ represents the total level of urbanization, housing prices, and affordable housing, $a_{i}, b_{i}$, and $c_{i}$ represent the weights of the three different subsystems, respectively, $\alpha, \beta$, and $\gamma$ represent the contributions of urbanization, housing prices, and affordable housing, respectively, and $\theta$ is an undetermined parameter. Following previous studies, the value of the parameter $\theta$ is set at 0.5 $[58,61,67-69]$.

The classification of the CCD between urbanization, housing prices, and affordable housing was established, as shown in Table 2. The values of the CCD range from 0 to 1 [66]. The classification is divided into four stages and ten types.

2.4. Data Source and Processing. Statistical data for calculation were obtained from the China Statistical Yearbook (2009-2019) (National Bureau of Statistics) and the China City Statistical Yearbook (2009-2019) (National Bureau of Statistics), while the 2008-2018 statistical data came from the National Health and Family Planning Commission Migrant Population Service Centre. Some indicator data
(N2, N6, and N8) were obtained from a secondary calculation of the statistical data.

After normalization of the research data, the corresponding weight values for the 12 indicators in the 3 subsystems were calculated using the trough entropy method. The results are shown in Table 3.

In Table 3, in the urbanization subsystem, the N2 indicator has the highest weight of all the indicators, from $\mathrm{N} 1$ to N4. This suggests that the N2 indicator has the greatest influence on the urbanization subsystem. In the housing price subsystem, there is not much difference in the weight values of the indicators; among them, N6 and N7 have similar weight values, as do N5 and N8. In the affordable housing subsystem, the $\mathrm{N} 11$ indicator has the highest weight value, followed by the N9 indicator, while the N10 indicator has the least weight value.

The trough weighted sum method was applied to the research data and corresponding weights values to obtain the comprehensive development levels of the three subsystems (urbanization, housing prices, and affordable housing) from 2008 to 2018. By using formula group (10), the detailed results' data are shown in Table 4.

To illustrate the development trend of the comprehensive development levels of the three subsystems from 2008 to 2018 more accurately, a broken line diagram was drawn, as shown in Figure 3. In the figure, the development trend of the urbanization subsystem $\left(\mu_{1}\right)$ shows fluctuation. For the housing price subsystem $\left(\mu_{2}\right)$, the comprehensive development level shows a stable development trend from 2008 to 2011, whereafter it starts to decline in 2012; in 2014, the comprehensive development level is in the trough of the trend; after 2014, the trend starts to rise steadily. For the affordable housing subsystem $\left(\mu_{3}\right)$, the whole trend of the comprehensive development level is on the rise.

Figure 3 shows that the comprehensive development level of the urbanization subsystem was in a state of fluctuating development. The comprehensive development level of housing prices was in a state of steady decline, followed by a rapid and persistent rise. For the affordable housing subsystem, the state of comprehensive development level is a wave-like upward trend.

To analyze the relationship between the three subsystems more reasonably, it is necessary to determine the development ratio and correlation coefficients $(\alpha, \beta, \gamma)$ of the three subsystems. Based on a literature review and previous 
TABLE 3: The weight of N1-N12 indicators of subsystems.

\begin{tabular}{lcc}
\hline Subsystem & Indicator & Weight \\
\hline \multirow{3}{*}{ Urbanization subsystem } & N1 & 0.1621 \\
& N2 & 0.4191 \\
& N3 & 0.1819 \\
Housing prices' subsystem & N4 & 0.2369 \\
& N5 & 0.2123 \\
& N6 & 0.2899 \\
Affordable housing subsystem & N7 & 0.2877 \\
& N8 & 0.2101 \\
& N9 & 0.2521 \\
& N10 & 0.2068 \\
& N11 & 0.2925 \\
& N12 & 0.2486 \\
\hline
\end{tabular}

TABLE 4: The comprehensive development levels of the subsystems.

\begin{tabular}{cccc}
\hline Year & $\mu_{1}$ & $\mu_{2}$ & $\mu_{3}$ \\
\hline 2008 & 0.4502 & 0.4061 & 0.1314 \\
2009 & 0.1395 & 0.4808 & 0.0844 \\
2010 & 0.6070 & 0.4341 & 0.4721 \\
2011 & 0.6657 & 0.4813 & 0.6133 \\
2012 & 0.4133 & 0.3403 & 0.5187 \\
2013 & 0.4708 & 0.3556 & 0.5912 \\
2014 & 0.4280 & 0.3001 & 0.5969 \\
2015 & 0.4011 & 0.3857 & 0.6117 \\
2016 & 0.4513 & 0.4774 & 0.7133 \\
2017 & 0.6233 & 0.5591 & 0.7384 \\
2018 & 0.6216 & 0.8135 & 0.7734 \\
\hline
\end{tabular}

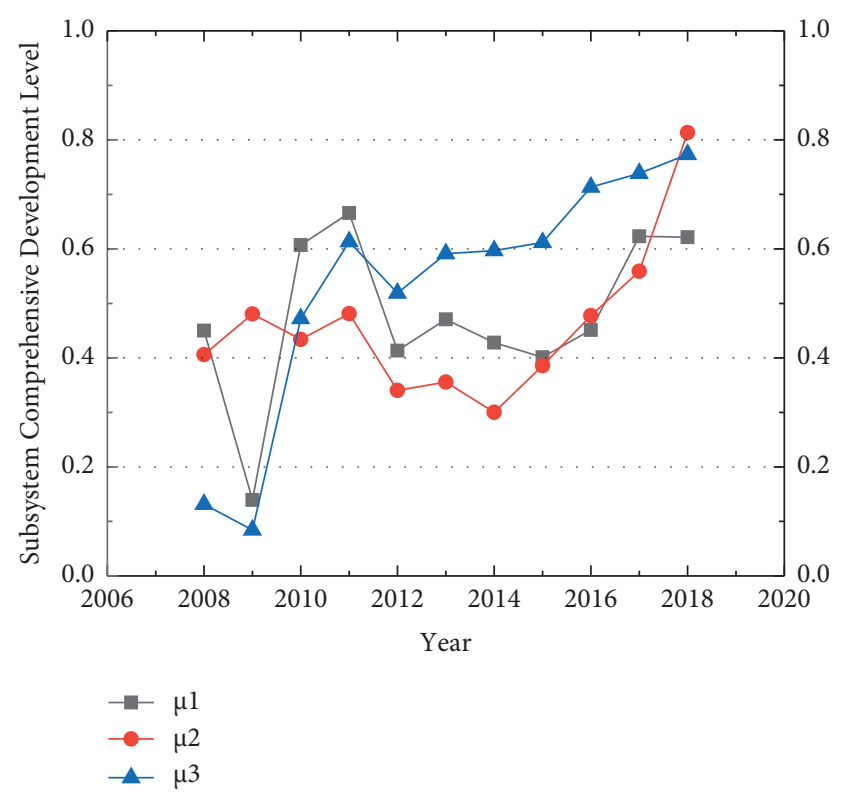

Figure 3: The comprehensive development levels of the subsystems.

studies, the real estate market in a developed country, such as the US, starts and develops rapidly, since the affordable housing system was established earlier. For such countries, the affordable and commercial housing systems have a stable, common development [70]. Additionally, the construction of the affordable housing system is relatively complete, with a relatively large investment in the construction scale. The contribution value ratio of affordable housing to housing prices in developed countries, such as the US, is about $3: 7$. Singapore, which is representative of newly industrialized countries, has a relatively perfect affordable housing system: the important value ratio of affordable housing to housing prices is about $2: 8$ [71].

In this study, urbanization is considered to be a subsystem in the analysis of the coupling coordination relationship in the system (urbanization, housing prices, and affordable housing). Hence, the contribution value of the urbanization subsystem should be chosen scientifically. Based on previous research $[8,72]$, urbanization has a close relationship with demand and supply in the real estate market, which, in turn, directly impacts housing prices. Considering the close coupling relationship between urbanization and housing prices, the contribution values of urbanization and housing prices in this study are almost the same.

In addition, following the literature, the values of $\alpha, \beta$, and $\gamma$ in this study are calculated based on the amount of investment in affordable housing in the real estate market $(\delta)$. As $\delta$ increases, the value of $\gamma$, among the three coefficients, increases. Hence, four sets of values for $\alpha, \beta$, and $\gamma$ are assigned for the four different ranges of $\delta$ to analyze the CCD of the system under different circumstances, as shown in Table 5. When the value of $\delta$ is small, the weight of affordable housing subsystem is weak, so the value of $\gamma$ is small. Hence, for this situation, this study sets the value of $\beta$ and $\gamma$ to 0.5 , which is the same as $\alpha$. When the value of $\delta$ increases continuously, the value of $\gamma$ increases, and this study sets the remaining value average to $\alpha$ and $\beta$.

\section{Results}

Based on the coupling coordination model, the coupling degree $(C)$, system development level $(T)$, and CCD $(D)$ were measured for four different coefficients (detailed information is listed in Table 6). The values of $T$ and $D$ in the composite system change slightly as the coefficients $(\alpha, \beta$, and $\gamma)$ change. From 2008 to 2018, the coupling degrees $(C)$ of the three subsystems are all high, with only the values for 2008 and 2009 below 0.9. The three subsystems have the lowest coupling degree (0.7587) in 2009. For the system development level $(T)$, the values under the four different coefficients show relatively little change. The trend of the system development level ( $T$ ) fluctuates from 2008 to 2016. The $T$ value trends upward from 2017, reaching its highest value in 2018 (0.7155| 0.7231| 0.7287| 0.7343); its lowest value occurs in 2009 (0.2903|0.2875|0.2650| 0.2424). In 2008, 2009, and 2010, with the increasing value of $\gamma$ and the decreasing values of $\alpha$ and $\beta$, the system development level (T) data show a slight decrease. In 2011, with $\gamma$ increasing and $\alpha$ and $\beta$ decreasing, the $T$ data show a downward trend, followed by an upward trend. After 2011, the $T$ data in each year show an upward trend, while the value of $\gamma$ increases and the values of $\alpha$ and $\beta$ decrease. 
TABLE 5: $\alpha, \beta$, and $\gamma$ values.

\begin{tabular}{lr}
\hline$\delta$ & $\alpha, \beta, \gamma$ value \\
\hline $1 \%-5 \%$ & $\alpha=0.5 \beta=0.45 \gamma=0.05$ \\
$5 \%-8 \%$ & $\alpha=0.45 \beta=0.45 \gamma=0.1$ \\
$8 \%-14 \%$ & $\alpha=0.4 \beta=0.4 \gamma=0.2$ \\
Over $14 \%$ & $\alpha=0.35 \beta=0.35 \gamma=0.3$ \\
\hline
\end{tabular}

TABLE 6: The coordinated degree of urbanization, housing prices, and affordable housing from 2008 to 2018.

\begin{tabular}{|c|c|c|c|c|c|c|c|c|c|}
\hline \multirow[t]{2}{*}{ Year } & \multirow[t]{2}{*}{$C$} & \multicolumn{2}{|c|}{$\begin{array}{l}\alpha=0.5, \beta=0.45 \\
\quad \text { and } \gamma=0.05\end{array}$} & \multicolumn{2}{|c|}{$\begin{array}{c}\alpha=0.45, \beta=0.45 \\
\quad \text { and } \gamma=0.1\end{array}$} & \multicolumn{2}{|c|}{$\begin{array}{c}\alpha=0.4, \beta=0.4, \text { and } \\
\gamma=0.2\end{array}$} & \multicolumn{2}{|c|}{$\begin{array}{l}\alpha=0.35, \beta=0.35 \\
\quad \text { and } \gamma=0.3\end{array}$} \\
\hline & & $T$ & $D$ & $T$ & $D$ & $T$ & $D$ & $T$ & $D$ \\
\hline 2008 & 0.8764 & 0.4144 & 0.6026 & 0.3984 & 0.5909 & 0.3688 & 0.5685 & 0.3391 & 0.5452 \\
\hline 2009 & 0.7587 & 0.2903 & 0.4693 & 0.2875 & 0.4671 & 0.2650 & 0.4484 & 0.2424 & 0.4288 \\
\hline 2010 & 0.9897 & 0.5225 & 0.7191 & 0.5157 & 0.7144 & 0.5109 & 0.7111 & 0.5060 & 0.7077 \\
\hline 2011 & 0.9908 & 0.5801 & 0.7581 & 0.5775 & 0.7564 & 0.5815 & 0.7590 & 0.5855 & 0.7616 \\
\hline 2012 & 0.9853 & 0.3857 & 0.6165 & 0.3910 & 0.6207 & 0.4052 & 0.6318 & 0.4194 & 0.6428 \\
\hline 2013 & 0.9789 & 0.4250 & 0.6450 & 0.4310 & 0.6495 & 0.4488 & 0.6628 & 0.4666 & 0.6758 \\
\hline 2014 & 0.9619 & 0.3789 & 0.6037 & 0.3874 & 0.6104 & 0.4107 & 0.6285 & 0.4339 & 0.6461 \\
\hline 2015 & 0.9776 & 0.4047 & 0.6290 & 0.4152 & 0.6371 & 0.4371 & 0.6536 & 0.4589 & 0.6698 \\
\hline 2016 & 0.9786 & 0.4761 & 0.6826 & 0.4893 & 0.6920 & 0.5141 & 0.7093 & 0.5390 & 0.7263 \\
\hline 2017 & 0.9934 & 0.6001 & 0.7721 & 0.6059 & 0.7758 & 0.6206 & 0.7852 & 0.6353 & 0.7945 \\
\hline 2018 & 0.9934 & 0.7155 & 0.8431 & 0.7231 & 0.8475 & 0.7287 & 0.8508 & 0.7343 & 0.8541 \\
\hline
\end{tabular}

To clearly analyze the degree of coupling coordination between the three subsystems, this study determined the coupling coordination classification and stage of the composite system from 2008 to 2018 under four different coefficient combinations, as shown in Figure 4. In Figure 4(a), the coupling stage is almost completely in the antagonism stage; only the 2009 CCD $(D)$ is below the running-in Stage; however, all the values in 2009 are higher than 0.4, which is close to the antagonism stage. From a coupling coordination classification perspective (as shown in Figure 4(b)), the levels from 2008 to 2018 under the four different coefficient combinations are above the marginal maladjustment classification. With the increasing coefficient ratio of the affordable housing subsystem $(\gamma)$, the coupling coordination classification in 2008 declines from initial coordination to reluctant coordination. The $D$ value in 2008 decreases from 0.6026 to 0.5452 . In 2016, when the value of $\gamma$ increases from 0.1 to 0.2 , the CCD is over 0.7 , changing from initial coordination to moderate coordination.

From the results of the system development level with the four different coefficients (as shown in Figure 5), the system development level generally shows an increasing trend with fluctuation. From 2008 to 2014, the system development level shows a fluctuating trend, with the value between 0.4 and 0.6. From 2014 to 2018, the system development level shows an upward trend and increases from 0.3789 to 0.7155 .

To illustrate the trend of the comprehensive CCD of the urbanization, housing price, and affordable housing subsystems from 2008 to 2018 more accurately, Figure 6 is drawn. Considering the broken line graph (Figure 6), the system CCD trends upward with fluctuation. From 2008 to 2009 , the CCD declined rapidly from almost 0.6 to less than
0.5 and then bounced back to over 0.7 in 2010. From 2010 to 2011 , the CCD of the three subsystems rose slowly and then dropped into the initial coordination classification (0.6-0.7). From 2012 to 2015, the CCD fluctuated mildly within the initial coordination classification (0.6-0.7). From 2015 to 2018, the CCD rose steadily from the initial coordination classification $(0.6-0.7)$ to the satisfactory coordination classification $(0.8-0.9)$.

\section{Discussion}

Sustainable development of urbanization plays an important role in urban social and economic development, which is also related to the degree of integration between the urban population and cities. Besides, as one of the key problems of population flow into cities, the residential housing problem also affects the process of sustainable development of urbanization. Furthermore, the coupling and coordination relationship between the supply of affordable housing and the prices of commercial housing in the real estate market, in the process of urbanization, has become a crucial research issue. However, commercial housing in China was proposed and has been implemented since the 1980s, while the policy on affordable housing has been implemented since 1999 . Compared with the real estate markets in other developed countries, China's originated late and developed relatively slowly. However, with the rapid development of China's society and economy, the Chinese government has increased investment in the construction of an affordable housing system to meet people's demand for basic housing. Therefore, the sustainable development of China's real estate market, against the background of rapid development, has become an area of immense research interest in recent years. 


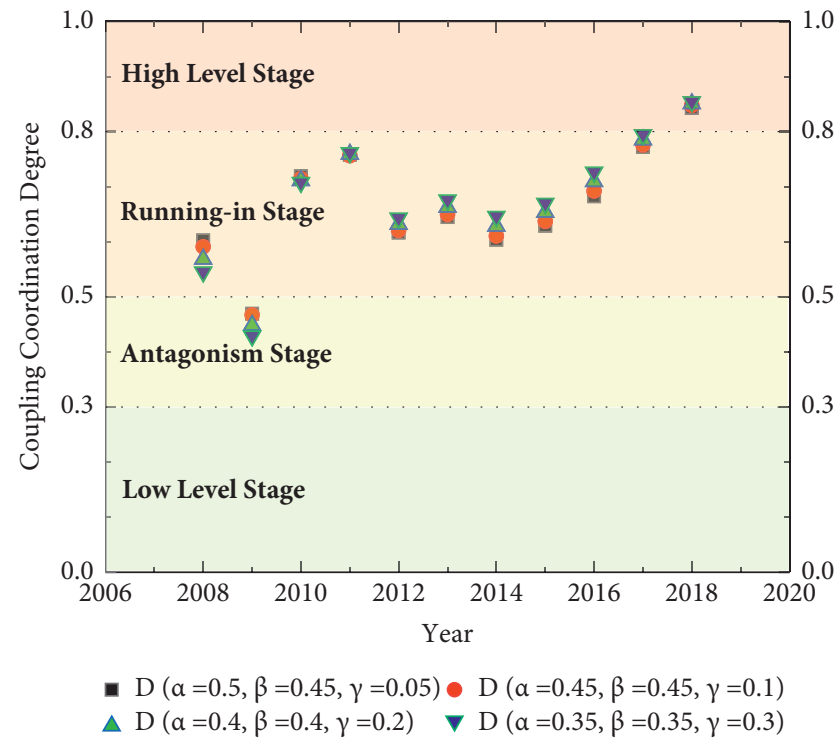

(a)

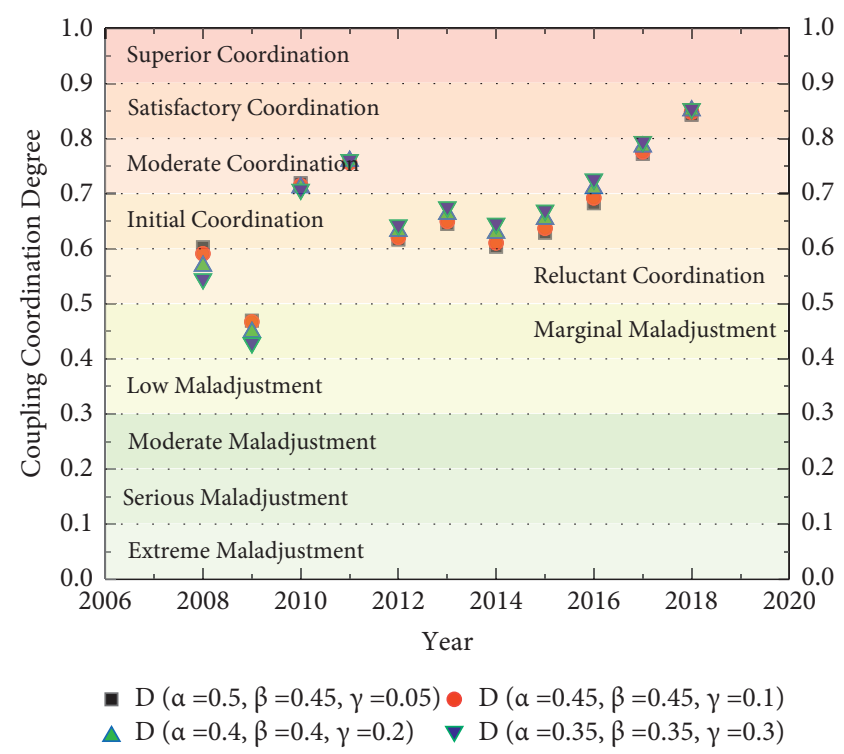

(b)

FIgURE 4: The classification of coordinated development of urbanization, housing prices, and affordable housing from 2008 to 2018.

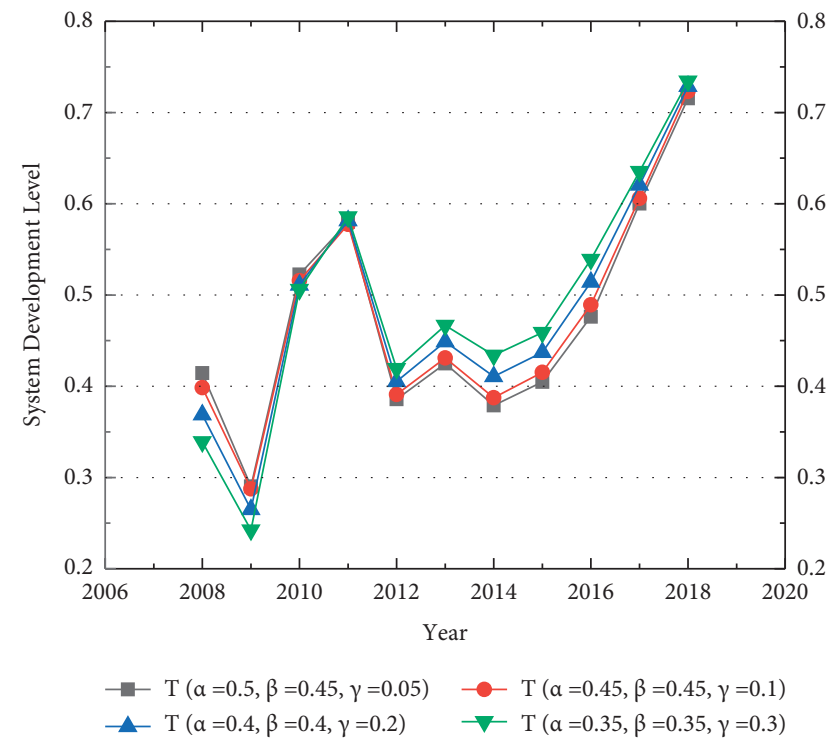

FIgURE 5: The system comprehensive development level from 2008 to 2018 with different coefficients.

As one of the important processes of national development, urbanization has a direct impact on national economic development. However, with the promotion of urbanization, the agglomeration of the urban population will lead to a shortage of regional resources and change the demographic age structure; furthermore, it will give rise to social problems. In this research, the economic development level indicator has the highest weight value in the evaluation indicator system, which means that the economic development level is an important indicator in the urbanization process. Li et al. and Liu et al., respectively, focus on the

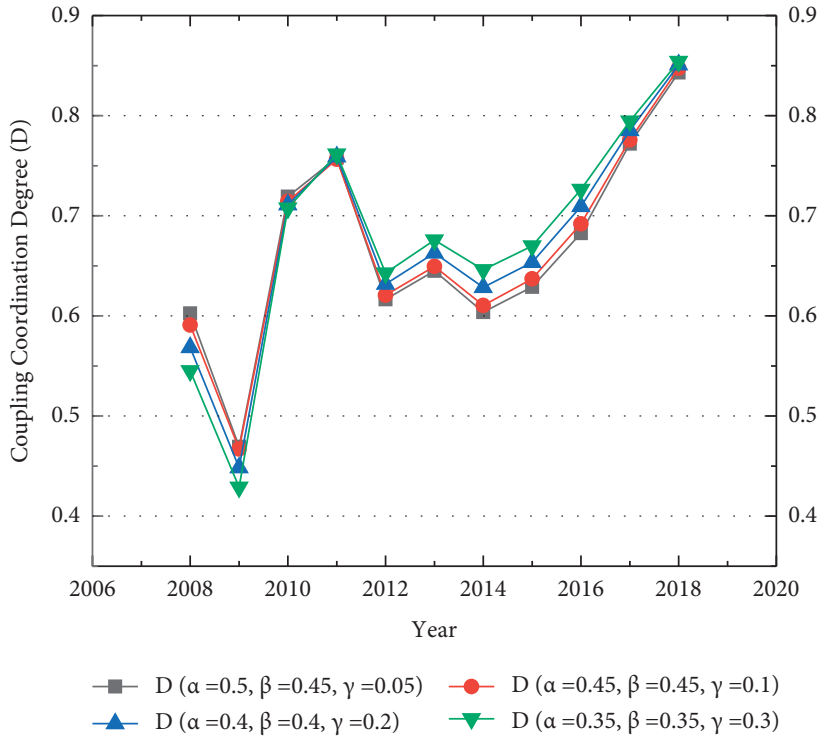

FIgURE 6: The CCD between urbanization, housing prices, and affordable housing from 2008 to 2018 with different coefficients.

impact of individual investment and population flow on housing prices in the urbanization process, demonstrating the close relationship between urbanization and housing prices $[73,74]$. In this study, the urbanization process and housing prices show high coupling in the system, which indicates that there is a close coupling coordination relationship between them.

Housing is one of the basic demands in people's lives. However, continuously rising housing prices lead to housing problems for low-middle-income groups that cannot be 
solved. In the current study, the comprehensive development levels of housing prices and affordable housing both increased from 2008 to 2018; the comprehensive development level of affordable housing has been increasing substantially since 2009. In 2008, the General Office of the State Council issued a document entitled "Several Opinions on Promoting the Healthy Development of the Real-Estate Market," which proposed to intensify the construction of affordable housing to improve people's living conditions and promote the sound development of the real estate market. Thereafter, relevant departments of the Chinese government successively issued policy documents on affordable housing and increased the investment in the construction of affordable housing; this provided housing for specific groups by means of government intervention, to meet people's basic housing demands and stabilize the development of the real estate market. The close relationship between housing prices and affordable housing is consistent with Torab's results, which show that the improvement and construction of affordable housing systems in developing countries can effectively control housing prices and help limit the occurrence of housing crises [75].

In the process of urbanization, the increasing urban population leads to an increase in housing demand. In the process, the inflow of people is mainly due to the import labor and newly graduated students, whose capital accumulation is inadequate for the purchase of commercial housing. Addressing the migrant population's housing demand has become a major problem in the process of urbanization. Improving the regional affordable housing system can help the migrant population solve the housing demand problem, facilitate the introduction of regional talents, and further promote the urbanization process. However, in the process of urbanization, the high housing prices and an incomplete affordable housing system will have a restraining effect on the population inflow. A sustainable development of urbanization is closely related to the construction of an affordable housing system. Wen and Wallace discuss the influence of affordable housing policy on the attraction of migrant population and the process of urban development from the perspective of relevant immigration policies in Shanghai; the authors find that, to expand the number of immigrant settlements and attract talents in urbanization, the government should improve the affordable housing system to ensure urban sustainable development and talent introduction [76].

This study evaluates the relationship among the urbanization, housing price, and affordable housing subsystems by selecting indicators of influence in the subsystems, comprehensively calculating the development level, and establishing the coupling coordination degree model. A high coupling and high coordination relationship between the urbanization process, housing prices, and affordable housing is demonstrated.

\section{Conclusions and Policy Implications}

The advancement of the urbanization process promotes the development of urban agglomeration in China, narrows the gap between urban and rural areas, adjusts the urban industrial structure, and promotes further development of the urban economy through the flow of people into cities [1]. However, urban population concentration increases housing demand and a rapid development of the real estate market. In the context of a rapid development of China's urbanization, the coupling coordination development of affordable housing and commercial housing is an important component of building a sustainable city. This study utilizes a CCD model and an entropy weight method to evaluate the comprehensive development level between urbanization, housing prices, and affordable housing and identifies the key factors of influence. Simultaneously, based on Chinese timeseries data from 2008 to 2018, the development process was simulated and analyzed. This study is the first attempt to examine the inter-relationships between these three subsystems in China. The main conclusions are as follows:

(1) The coupling degree of urbanization, housing prices, and affordable housing, from 2008 to 2018, is high ( $\geq 0.8764)$, except in 2009 (0.7587), which illustrates that the three subsystems promote and restrict each other during the period 2008-2018. Based on the examination of the comprehensive development level of the three subsystems, it is found that one or two subsystem comprehensive development levels are extremely low, i.e., the coupling degree of the system is low. Therefore, when all three subsystems develop, the internal coupling relationship of the research system reaches a high level.

(2) The CCD between urbanization, housing prices, and affordable housing from 2008 to 2018 is high $(\geq 0.4)$, which means that the three subsystems influence and promote each other well. In addition, the CCD of the system gradually rises (from marginal maladjustment (0.4-0.5) to satisfactory coordination (0.8-0.9)) as the central and local governments increase the input for local residents' housing security. It further shows that the intervention of the affordable housing system in China's urbanization process can effectively restrict the real estate market prices and realize a sustainable development of the urban housing market.

Based on the CCD evaluation analysis, a dynamic evolution of the system can be simulated to further analyze the inter-relationships between urbanization, housing prices, and affordable housing and to demonstrate the effect of macrocontrol of the real estate market on the process of urbanization.

Based on the above research conclusions, the following policy implications are proposed:

(1) The impact of urbanization on the real estate market, whether due to direct or indirect influences, conclusively results in an imbalance between supply and demand in the regional real estate market, which further impacts housing prices. To solve the imbalance problem and control the excessively rapid rise of housing prices, central and local governments should construct affordable housing to meet the 
different levels of housing demand of local residents. However, the current affordable housing supply system is relatively unitary and cannot more scientifically and reasonably balance the demand for affordable housing by the local low-income groups and the migrant population. To better manage residents' housing demand in the process of urbanization, local government should provide different levels of affordable housing, based on the actual situation of different families and individual conditions and characteristics (such as the urbanization rate, the low-and-middle-income groups, and the migration of population group).

(2) In the process of the continuous development of China's real estate market, the rapidly increasing housing prices turn housing into a rapidly growing investment product, which leads to a weakening of the consumption attributes of housing and a strengthening of the investment attributes of housing. To weaken the investment attribute and strengthen the consumption attribute of housing, local governments should introduce appropriate purchase restriction policies based on local residents' living standards, balance the supply and demand relationship and, furthermore, control the housing prices. On the contrary, to ensure the development of urbanization and the regional economy under the policy of housing price control, the local government should, additionally, introduce a series of relevant policies on talent introduction, while controlling housing prices, and ensure the demand for basic housing by imported residents (imported talent) is met, through preferential loans or a housing allowance.

(3) Urban land planning is an essential link in the process of urbanization; it determines the urban structure and affects the sustainable development of a city. According to the results of this study, there is a high degree of coupling coordination relationship between urbanization, housing prices, and affordable housing. Presently, the supply of urban affordable housing is mainly aimed at the housing demand of local residents, while less consideration is given to the subjective factor of population urbanization, which will indirectly inhibit the sustainable development of urbanization. Local government should seek an enterprise-government cooperation mechanism to attain a complete set of commercial and affordable housing construction on a scientific and reasonable basis, with appropriate urban land planning to ensure housing supply in the urbanization process; such a mechanism would realize a stable development of urbanization, commercial housing, and affordable housing.

As a large developing country with rapid economic development, China has a large population and a vast territory. In the urbanization process in China, uneven regional development has emerged, and some social problems, such as the problem of housing demand, have become the focus of scholars' attention. As a rapidly developing country, the coupling coordination mode between urbanization and the real estate market in China is of significance for other developing countries. This study constructed a coupling coordination model to evaluate the inter-relationships between urbanization, housing prices, and affordable housing, with a degree of success; however, some limitations remain. (1) National data were used for this study. Given the uneven regional development in China, the research results on urbanization, housing prices, and affordable housing lack specific regional relevance. (2) The internal structure and dynamic simulation of the system were not considered, while the changes in time, space, and function caused by the synergies within the system were ignored. As an experiment, future research can extend this study by constructing system dynamics among multiple subsystems, combined with a prediction model to establish the common law of the orderly transformation of the system structure, thus improving the research.

\section{Data Availability}

Statistical data for calculation were obtained from the China Statistical Yearbook (2009-2019) (National Bureau of Statistics) and the China City Statistical Yearbook (2009-2019) (National Bureau of Statistics), while the 2008-2018 statistical data were obtained from the National Health and Family Planning Commission Migrant Population Service Centre. Some indicator data were obtained from a secondary calculation of the statistical data.

\section{Conflicts of Interest}

The authors declare no conflicts of interest.

\section{Authors' Contributions}

Lida Wang investigated the study and wrote, reviewed, and edited the original draft. Xian Rong collected the resources, supervised the study, and reviewed the study. Lingling $\mathrm{Mu}$ developed the methodology andcurated the data.

\section{Acknowledgments}

The study was supported by the National Natural Science Foundation of China (NSFC) (71904042) and Science and Technology Research Project of Government-subsidized Housing Project in Hebei Province (2017-016 and 2018-012).

\section{References}

[1] H. Han and H. Li, "Coupling coordination evaluation between population and land urbanization in Ha-Chang urban agglomeration," Sustainability, vol. 12, no. 1, p. 357, 2020.

[2] C. Li and P. Li, "Sustainable development of urban agglomeration in China: from concept to evaluation," Journal of Chongqing University (Social Science Edition), vol. 24, pp. 1-12, 2018.

[3] S. Yao, Z. Chen, and Y. Zhu, "Social sustainability: a new conceptual framework," Sustainability, vol. 9, p. 68, 2017. 
[4] Q. Wan, C. Wu, and J. Zeng, "Study on the urbanizaiton efficiency and determinants of China's urban agglomerations," China Population Resources and Environment, vol. 25, no. 2, pp. 66-74, 2015.

[5] National Bureau of Statistics, China Statistical Yearbook 2019, 2020, http://www.stats.gov.cn/tjsj/ndsj/2019/indexch.htm, in Chinese.

[6] National Health and Family Center, Total Migrant Population in 2017, 2020, http://www.chinaldrk.org.cn/wjw/\#/home, in Chinese.

[7] Y. Liu and K. W. Chau, "The impact of urbanization on investment of real estate industry in China," Proceedings of the 20th International Symposium on Advancement of Construction Management and Real Estate, Springer, Singapore, pp. 521-530, 2017.

[8] Y. Lin, Z. Ma, K. Zhao, W. Hu, and J. Wei, "The impact of population migration on urban housing prices: evidence from China's major cities," Sustainability, vol. 10, no. 9, p. 3169, 2018.

[9] J. Zhang and L. Zhou, "Incentive mechanism design of access management policy in affordable housing and analysis," Cities, vol. 28, no. 2, pp. 186-192, 2011.

[10] J. Xi, "Secure a decisive victory in building a moderately prosperous society in all respects and strive for the great success of socialism with Chinese characteristics for a new era," in Proceedings of the Opening Address to the 19th $\mathrm{Na}$ tional Congress of the Communist Party of China, Beijing, ChinaOctober 2017, in Chinese.

[11] K. Li: Report on the Work of the Government, 2020, http:// www.gov.cn/guowuyuan/zfgzbg.htm, in Chinese.

[12] J. Zhou, H. Zhang, Y. Gu, and A. A. Pantelous, "Affordable levels of house prices using fuzzy linear regression analysis: the case of Shanghai," Soft Computing, vol. 22, no. 16, pp. 5407-5418, 2018.

[13] X.-R. Wang, E. C.-M. Hui, and J.-X. Sun, "Population migration, urbanization and housing prices: evidence from the cities in China," Habitat International, vol. 66, pp. 49-56, 2017.

[14] J. Li and Y. Xu, "Evaluating restrictive measures Containing housing prices in China: a data envelopment analysis approach," Urban Studies, vol. 53, no. 12, pp. 2654-2669, 2016.

[15] F. Liu, S. Matsuno, R. Malekian, J. Yu, and Z. Li, “A vector auto regression model applied to real estate development investment: a statistic analysis," Sustainability, vol. 8, no. 11, p. 1082, 2016.

[16] F. Ulah and S. E. Sepasgozar, "Key factors influencing purchase or rent decisions in smart real estate investments: a system dynamics approach using online forum thread data," Sustainability, vol. 12, no. 11, p. 4382, 2020.

[17] X. Xiong, H. Guo, and X. Hu, "The housing demand analysis and prediction of the real estate based on the AWGM $(1, \mathrm{~N})$ model," Grey Systems: Theory and Application, vol. 11, no. 2, pp. 222-240, 2020.

[18] Y. Zou, "Air pollution and housing prices across Chinese cities," Journal of Urban Planning and Development, vol. 145, no. 4, Article ID 04019012, 2019.

[19] C. Wu, F. Ren, W. Hu, and Q. Du, "Multiscale geographically and temporally weighted regression: exploring the spatiotemporal determinants of housing prices," International Journal of Geographical Information Science, vol. 33, no. 3, pp. 489-511, 2019.

[20] L. Chen, X. Yao, Y. Liu et al., "Measuring impacts of urban environmental elements on housing prices based on multisource data-a case study of Shanghai, China," ISPRS
International Journal of Geo-Information, vol. 9, no. 2, p. 106, 2020.

[21] X. Zhang, X. Liu, J. Hang, D. Yao, and G. Shi, "Do urban rail transit facilities affect housing prices? Evidence from China," Sustainability, vol. 8, no. 4, p. 380, 2016.

[22] J.-W. Zhu, B. Chen, P. Lu, J.-L. Liu, and G. Tang, "Impact of urban water system treatment on the surrounding residential land price," Arabian Journal of Geosciences, vol. 11, no. 1, p. 6, 2018.

[23] X. Gong, Y. Li, Y.-C. Wu, and W.-S. Yang, "Pricing various types of mortgage insurances with disposal and discount costs under a mean-reverting Lévy housing price process," Physica A: Statistical Mechanics and Its Applications, vol. 551, Article ID 124561, 2020.

[24] Y. H. Zhang and D. C. Zheng, "Study on the relationship between urbanization and real estate market demands," Special Zone Economy, vol. 12, pp. 277-279, 2009.

[25] W. T. Wang, "Analysis of the impact of urbanization on Chinese real estate market demands," Modern Property Management, vol. 4, pp. 21-23, 2010.

[26] W. Gong, C. Xu, and H. Wang, "How does the urbanization pro up China's housing prices?-A spatial econometric analysis based on urbanization's decomposition," Inquiry into Economic Issues, vol. 03, pp. 63-76, 2019, in Chinese.

[27] J. Wang and Q. Xu, "The influence of floating population on real estate prices: an empirical study of beijing," in DEStech Transactions on Social Science Education and Human Science, M. Pavlova, J. Liu, X. Y. Zeng, and M. Pavlova, Eds., DEStech Publishing Inc., Lancaster, PA, USA, pp. 112-118, 2017.

[28] L. Wang and W. Chen, "A PVAR study on the relationship between housing price and population mobility," Modern Urban Research, vol. 6, pp. 9-15, 2018, in Chinese.

[29] W. Ren and L. Chen, "Income gap, housing prices and economic growth," Journal of East China University of Science and Technology, vol. 34, no. 1, pp. 74-81, 2019, in Chinese.

[30] C. M. Nicholls, "Housing, homelessness and capabilities," Housing, Theory and Society, vol. 27, no. 1, pp. 23-41, 2010.

[31] L. Tian, Z. Yao, C. Fan, and L. Zhou, "A systems approach to enabling affordable housing for migrants through upgrading Chengzhongcun: a case of Xiamen," Cities, vol. 105, Article ID 102186, 2018.

[32] P. King, "Housing as a freedom right," Housing Studies, vol. 18, no. 5, pp. 661-672, 2003.

[33] United Nations, "New urban agenda: habitat III," 2016.

[34] M. Murray, "Subsidized and un-subsidized housing stocks 1935 to 1987: crowding out and contegration," The Journal of Real Estate Finance and Economics, vol. 18, pp. 107-124, 1999.

[35] C. I. Lee, "Does provision of public rental housing crowding out private housing investment panel VAR approach," Journal of Housing Economics, vol. 16, pp. 1-20, 2007.

[36] S. Susin, "Rent vouchers and the price of low-income housing," Public Economics, vol. 83, pp. 109-152, 2003.

[37] A. Laferrère and D. Le Blanc, "How do housing allowances affect rents? An empirical analysis of the French case," Journal of Housing Economics, vol. 13, no. 1, pp. 36-67, 2004.

[38] A. Crews Cutts and E. O. Olsen, "Are section 8 housing subsidies too high?” Journal of Housing Economics, vol. 11, no. 3, pp. 214-243, 2002.

[39] T. Sinai and J. Waldfogel, "Do low-income housing subsidies increase the occupied housing stock?" Journal of Public Economics, vol. 89, no. 11-12, pp. 2137-2164, 2005.

[40] H. Zhang, "Land supply, public housing provision and housing price," Social Sciences in Chinese Higher Education Institutions, vol. 6, pp. 58-68, 2019, in Chinese. 
[41] X. Luo, S. Ma, and W. Wang, "Research on the influence on Comercial housing price from affordable housing-based on the perspective of supply and demand combination," Soft Science, vol. 27, no. 10, pp. 1-4, 2013.

[42] Y. Liu and J. Li, "Does affordable housing lower the housing price?-empirical evidence based on dynamic panel threshold model," Review of Economy and Mangement, vol. 33, no. 5, pp. 5-11, 2017, in Chinese.

[43] B. Wang and H. Jiang, "Research on the transmission mechanism of affordable housing construction to commercial housing price," Price Theory \& Practice, vol. 2, pp. 92-94, 2016, in Chinese.

[44] R. A. Meyers, Encyclopedia of Complexity and Systems Science, Springer, Berlin, Germany, 2009.

[45] S. Xiong, Y. Wu, S. Wu, F. Chen, and J. Yan, "Determinants of migration decision-making for rural households: a case study in Chongqing, China," Natural Hazards, vol. 104, no. 2, pp. 1623-1639, 2020.

[46] L. Ma, F. Jin, Z. Song, and Y. Liu, "Spatial coupling analysis of regional economic development and environmental pollution in China," Journal of Geographical Sciences, vol. 23, no. 3, pp. 525-537, 2013.

[47] D. Wang, D. Jiang, J. Fu, G. Lin, and J. Zhang, "Comprehensive assessment of production-living-ecological space based on the coupling coordination degree model," Sustainability, vol. 12, no. 5, p. 2009, 2020.

[48] Y. Geng, M. Maimaituerxun, and H. Zhang, "Coupling coordination of water governance and tourism: measurement and prediction," Discrete Dynamics in Nature and Society, vol. 2020, Article ID 3683918, 13 pages, 2020.

[49] X. Wang and D. Liu, "The coupling coordination relationship between tourism competitiveness and economic growth of developing countries," Sustainability, vol. 12, no. 6, p. 2350, 2020.

[50] Z. Zhang and Y. Li, "Coupling coordination and spatiotemporal dynamic evolution between urbanization and geological hazards-a case study from China," The Science of the Total Environment, vol. 728, Article ID 138825, 2020.

[51] J. Wang, S. Wang, S. Li, and K. Feng, "Coupling analysis of urbanization and energy-environment efficiency: evidence from guangdong province," Applied Energy, vol. 254, Article ID 113650, 2019.

[52] J. Liu, X. Jin, W. Xu et al., "A new framework of land use efficiency for the coordination among food, economy and ecology in regional development," The Science of the Total Environment, vol. 710, Article ID 135670, 2020.

[53] D. Zhou, J. Xu, and Z. Lin, "Conflict or coordination? Assessing land use multi-functionalization using productionliving-ecology analysis," The Science of the Total Environment, vol. 577, pp. 136-147, 2017.

[54] B. Peng, X. Sheng, and G. Wei, "Does environmental protection promote economic development? From the perspective of coupling coordination between environmental protection and economic development," Environmental Science and Pollution Research, vol. 27, no. 31, pp. 39135-39148, 2020.

[55] M. Xu and W.-Q. Hu, "A research on coordination between economy, society and environment in China: a case study of jiangsu," Journal of Cleaner Production, vol. 258, Article ID 120641, 2020.

[56] N. Chen, F. Qin, Y. Zhai, H. Cao, R. Zhang, and F. Cao, "Evaluation of coordinated development of forestry management efficiency and forest ecological security: a spatiotemporal empirical study based on China's provinces,"
Journal of Cleaner Production, vol. 260, Article ID 121042, 2020.

[57] Y. Geng, H. Zhu, N. Zhao, and Q. Zhai, "A new framework to evaluate sustainable higher education: an analysis of China," Discrete Dynamics in Nature and Society, vol. 2020, Article ID 6769202, 14 pages, 2020.

[58] L. Jiang, L. Bai, and Y. M. Wu, "Coupling and coordinating degrees of provincial economy, resources and environment in China," Journal of Natural Resources, vol. 32, no. 5, pp. 788-799, 2017.

[59] D. Li, H. Chen, E. C. Man Hui, H. Yang, and Q. Li, “A methodology for ex-post assessment of social impacts of an affordable housing project," Habitat International, vol. 43, pp. 32-40, 2014.

[60] J. Du and H. Shi, "Research on coupling coordination of the affordable housing market and Commercialized housing market," Journal of Engineering Man agement, vol. 27, no. 3, pp. 86-91, 2013, in Chinese.

[61] A. P. C. Chan and M. A. Adabre, "Bridging the gap between sustainable housing and affordable housing: the required critical success Criteria (CSC)," Building and Environment, vol. 151, pp. 112-125, 2019.

[62] E. Mulliner and V. Maliene, "An analysis of professional perceptions of criteria contributing to sustainable housing affordability," Sustainability, vol. 7, pp. 248-270, 2015.

[63] L. Ning, "Empirical study on the relation between house prices and rent on the basis of the real estate market's endogenous properties," Contemporary Economic Management, vol. 36, no. 3, 2014.

[64] X. Guo, "Application of improved entropy method in evaluation of economic result," Systems Engineering: Theory \& Practice, vol. 12, pp. 99-103, 1998.

[65] Y. Li, Y. Li, Y. Zhou, Y. Shi, and X. Zhu, "Investigation of a coupling model of coordination between urbanization and the environment," Journal of Environmental Management, vol. 98, pp. 127-133, 2012.

[66] L. Gan, H. Shi, Y. Hu, B. Lev, and H. Lan, "Coupling coordination degree for urbanization city-industry integration level: sichuan case," Sustainable Cities and Society, vol. 58, Article ID 102136, 2020.

[67] T. Shi, S. Yang, W. Zhang, and Q. Zhou, "Coupling coordination degree measurement and spatiotemporal heterogeneity between economic development and ecological environment-Empirical evidence from tropical and subtropical regions of China," Journal of Cleaner Production, vol. 244, Article ID 118739, 2020.

[68] Y. Geng and Y. Tan, "Measurement and prediction: coupling coordination of finance and air environment," Discrete Dynamics in Nature and Society, vol. 2020, Article ID 8673965, 12 pages, 2020.

[69] X. Zhu, Z. Zhao, and R. Yan, "Coupling coordinated development of population, marine economy, and environment system: a case in Hainan province, China," Journal of Coastal Research, vol. 98, no. 1, pp. 18-21, 2019.

[70] S. Mu and H. Cheng, "Housing security analysis from the perspectives of supply and demand," Journal of Engineering Management, vol. 24, no. 2, pp. 191-195, 2010, in Chinese.

[71] Y. S. Zhang, Y. J. Zhang, and Q. Jia, "Study on coordination of the affordable and commercialized housing market under the background of coordinated development of beijing, tianjin and Hebei based on coupling model," Journal of Engineering Management, vol. 32, no. 3, pp. 141-146, 2018, in Chinese.

[72] Y. Zhang, H. Jin, Y. Xiao, and Y. Gao, "What are the effects of demographic structures on housing consumption?: evidence 
from 31 provinces in China," Mathematical Problems in Engineering, vol. 2020, Article ID 6974276, 14 pages, 2020.

[73] J. Li, J. Ji, H. Guo, and L. Chen, "Research on the influence of real estate development on private investment: a case study of China," Sustainability, vol. 10, no. 8, p. 2659, 2018.

[74] T. Liu, H. Liu, and Y. Qi, "Construction land expansion and cultivated land protection in urbanizing China: insights from national land surveys, 1996-2006," Habitat International, vol. 46, pp. 13-22, 2015.

[75] E. S. Torab, "A law or just a hypothesis? A critical review of supply and demand effect on the affordable residential markets in developing countries," Alexandria Engineering Journal, vol. 57, no. 4, pp. 4081-4090, 2018.

[76] C. Wen and J. L. Wallace, "Toward human-centered urbanization? Housing ownership and access to social insurance among migrant households in China," Sustainability, vol. 11, no. 13, Article ID 3567, 2019. 